\title{
Classification of tree species composition using a combination of multispectral imagery and airborne laser scanning data
}

\author{
Maroš Sedliak*, Ivan Sačkov, Ladislav Kulla \\ National Forest Centre - Forest Research Institute Zvolen, T. G. Masaryka 2175/22, SK - 96092 Zvolen, Slovak Republic
}

\begin{abstract}
Remote Sensing provides a variety of data and resources useful in mapping of forest. Currently, one of the common applications in forestry is the identification of individual trees and tree species composition, using the object-based image analysis, resulting from the classification of aerial or satellite imagery. In the paper, there is presented an approach to the identification of group of tree species (deciduous - coniferous trees) in diverse structures of close-to-nature mixed forests of beech, fir and spruce managed by selective cutting. There is applied the object-oriented classification based on multispectral images with and without the combination with airborne laser scanning data in the eCognition Developer 9 software. In accordance to the comparison of classification results, the using of the airborne laser scanning data allowed identifying ground of terrain and the overall accuracy of classification increased from $84.14 \%$ to $87.42 \%$. Classification accuracy of class "coniferous" increased from $82.93 \%$ to $85.73 \%$ and accuracy of class "deciduous" increased from $84.79 \%$ to $90.16 \%$.
\end{abstract}

Key words: object-based classification; tree species; aerial images; airborne laser scanning

Editor: Bohdan Konôpka

\section{Introduction}

A trend in forest mapping is the use of modern means of computer and digital measuring technique. This trend is also reflected in the field of remote sensing (RS) and digital photogrammetry, which methods are now irreplaceable in addition to the terrestrial methods of forest mapping and gathering the information about the forest for forest management purposes. The development of remote sensing technology, and remote sensing data itself, has allowed replace or combine the terrestrial methods with time and cost-efficient remote sensing methods, using the aerial photographs, satellite imagery or airborne laser scanning (ALS) data (Maltamo \& Packalen 2014).

One of the most frequently used and effective methods of derivation of tree and stand characteristics from the remote sensing data is image segmentation and classification. Currently, the object-based image analysis (OBIA) is more preferred method than the pixel classification (Yu et al. 2006; Petr et al. 2010; Pippuri et al. 2016). Pixel classification is based on the classifying the individual pixels to particular classes in accordance to their digital numbers (DN). On the other hand, the OBIA method works with objects (segments), which are represented by clusters of pixels with similar properties (brightness, texture, homogeneity, size, shape, etc.)
(Benz et al. 2004). The objects can better represent the real objects, which are the subject of forestry mapping (e.g. tree crowns, forest stands), what is confirmed in a number of previously published works (Blaschke 2010). Using the OBIA method, there were achieved better results of forest and landscape classification, in an average of several tens of percent (Cleve et al. 2008; Myint et al. 2011; Rittl et al. 2013). Worse results related to the accuracy of pixel-based classification were achieved due to the fact that inside the identified tree crowns may occur pixels representing the shadow, errors or noise, i.e. the “salt and pepper" effect (Heinzel \& Koch 2012). This problem is even more severe when using RS data with very high resolution, which provide more detailed spatial and radiometric information about the displayed objects (Kim \& Madden 2006; Myint et al. 2011).

At present, almost $90 \%$ of the mapping works in the Slovak Republic territory is carried out by photogrammetric methods (Halvoñ 2011). Nevertheless, the common applications of remote sensing methods include classification of land cover, forest health, tree species composition and forest structure and texture (Wang \& Boesch 2007; Bucha et al. 2010) are applied more in the research than in practice so far. Majlingová (2007) dealt with the classification of analogue colour infrared images followed by the subsequent surveys, respectively esti- 
mating the tree and stand characteristics. Based on the results achieved, she indicated that the most appropriate resolution for the classification of tree species composition in mature stands is the spatial resolution of at least $1.6 \mathrm{~m}$. She also highlights the importance of identifying a suitable scale factor (scale parameter) for segmenting the input images in Definiens eCognition software, with respect in particular to the stand age, tree species composition, and therefore the parameters of expected size of tree crown.

Kardoš et al. (2013) have studied the classification of tree species in the eCognition software on the unmanaged land with great diversification of tree species and diverse horizontal and vertical structure. They compared the impact of different types of spatial resolution and aerial imagery on their segmentation and classification results, using multiple classification techniques.

An important area of remote sensing, applied in the mapping of forests, is the ALS, which provides useful information on the forest as for the needs of forest management as for forest mapping (Wack et al. 2003; Andersen \& Breindenbach 2007; Korpela et al. 2007). The ALS technology uses the reflection of laser ray from the object, and based on the relatively high density of the transmitted rays (up to several tens of points per $1 \mathrm{~m}^{2}$ ), with a relatively high positioning accuracy of the reflection in the 3D space (X, Y, Z), it provides, in particular, an accurate position information on sensed objects, that allows determine their shape and position more precisely. This information is useful for the derivation of Digital Surface Models (DSM) or the shape of individual objects. In addition, it is also possible to evaluate the intensity of the reflected ray, which relates to the nature of the surface (foliage type, leaf size, leaf orientation) (Fassnacht et al. 2016). For forestry purposes, it is suitable to combine this data with radiometric qualitative information about the objects, determined e.g. from the multispectral images, which can increase the accuracy of tree crowns identification or derivation of other tree and stand characteristics (Kressler \& Steinnocher 2006; Tiede et al. 2006; Sasaki et al. 2012; Debella-Gilo et al. 2013; Machala \& Zejdova 2014; Pippuri et al. 2016).

Leppänen et al. (2008) used the ALS data in combination with CIR images to delineate the forest stands. CIR imagery improves the classification of different tree species types, the ALS data alone provides a good conditions for derivation of timber size and density. Wang et al. (2012) used a combination of aerial photography and ALS to derive the borders by the Gabor wavelets, while the key features were Curvature features, derived from ALS. Ørka et al. (2012) used the ALS data combined with LANDSAT-5 data for mapping the subalpine zone. Classification of the ALS data enabled the accurate depiction of the zone over a large area, without calibration based on the field measurements.

The aim of this study is to evaluate the impact of ALS data application, in combination with aerial multispectral imagery, on the accuracy of the classification of tree species composition (defined as two groups: coniferous and deciduous tree species) in conditions of close-to-nature mixed forests of beech, fir and spruce. The presumption is that the combination of both data sources will have a positive impact on the accuracy of group of tree species composition classification.

\section{Material and methods}

\subsection{Experimental area}

The experimental area is located in the territory of the "Pro Silva" demonstration object - Smolnícka Osada (48 $44^{\prime}$ N , 20 46' E) in Slovakia, where the close-tonature forest management is carried out for more than 50 years (Fig. 1). The total extent of this area is 2,223 hectares. The area is located in Volovske vrchy orographic region. It has mountainous nature with altitudes in the range of 443-1,150 mabove sea level. Regarding vegetation zones, the $5^{\text {th }}$ (fir-beech) and $4^{\text {th }}$ (beech) altitudinal vegetation zones prevail. Commercial forests represent $65 \%$ of the area, special purpose forests aimed at protection of genetic resources $24 \%$, rest are protective forest. Tree species representation in the highest storey is as follows:Abies alba-37\%, Fagus sylvatica-37\%, Picea abies - 12\%, Pinus sylvestris - 10\%. Over all area, 50 circular verification plots with diameter $25 \mathrm{~m}$ were established to cover variability of stand characteristics (Fig. 1).

\subsection{Remote sensing data}

To obtain the multispectral aerial images with a spatial resolution of $9,000 \times 6,732$ pixels, there was used the Leica RCD30 camera. Aerial photography was carried out in September 2014, using the Cessna TU206F supporting device in an average flight altitude of 1,034 m. In further processing, the images were orthorectified and mosaicked, what resulted in creation of two raster layers - colour orthophoto (RGB) and colour infrared orthophoto (CIR) with a spatial resolution of $0.2 \mathrm{~m}$ and 16-bit colour depth, which served as the input data for the classification process.

The second input remote sensing data included the data from the airborne laser scanning (ALS), which was carried out in parallel with the multispectral photographs. To obtain the point clouds, there was the Leica ALS 70-CM laser scanner used, which at an angle of $49^{\circ}$ (FOV) and $228.4 \mathrm{kHz}$ (PRF) frequency ensured the density of 4.3 point $/ \mathrm{m}^{2}$. In the next working process, two raster files with $0.5 \mathrm{~m}$ resolution were calculated from the point cloud. The first one is the normalised digital surface model (nDSM), which is derived by subtracting the digital terrain model (DTM) from the digital surface model (DSM). Creating of digital models was carried out through hierarchic robust filtering techniques in 


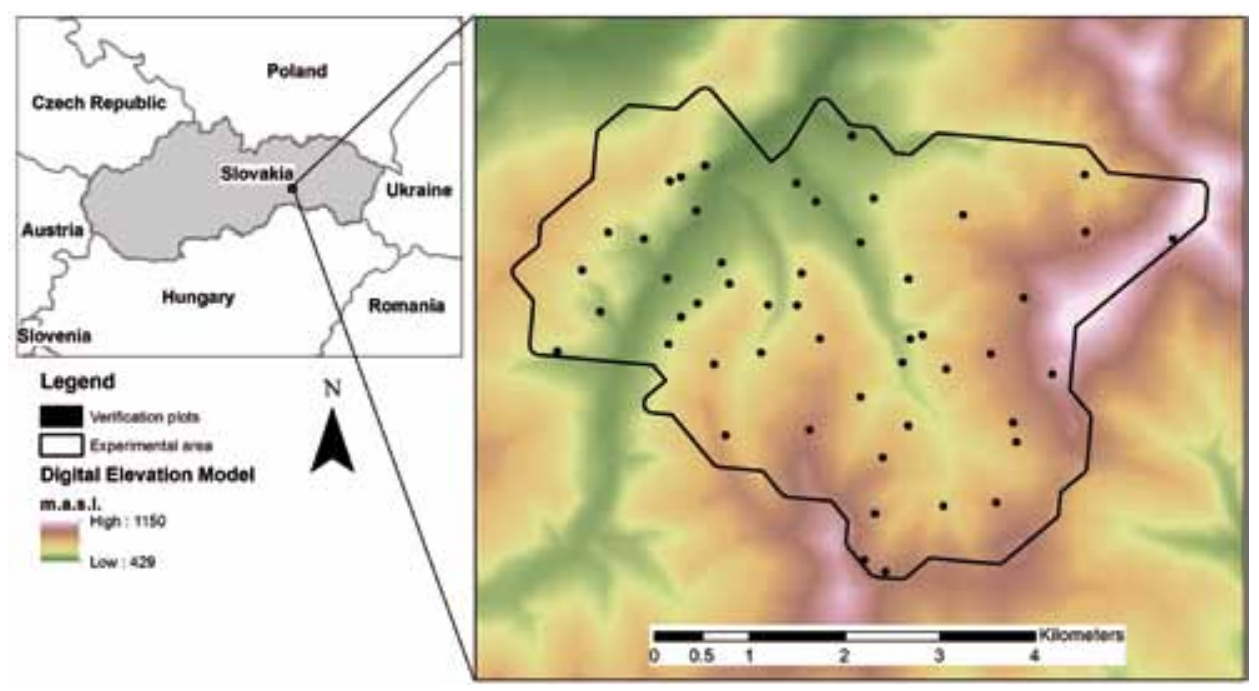

Fig. 1. Localization of experimental area and verification plots.

SCOP++ environment (Trimble). The second one is the intensity raster, which is created based on intensity values collected for every point in the point cloud. Creating of intensity raster was carried out using the geoprocessing tools in ArcGIS (ESRI).

\subsection{Segmentation process}

The first step in the process of group of tree species classification was the image segmentation. Segmentation was performed in eCognition Developer 9 software, using the "Multiresolution Segmentation" algorithm, which is based on Fractal Net Evolution Approach (FNEA) (Baatz \& Schäpe 2000). Due to the large extent of the area and software limits for image processing, these images were automatically divided into 9 tiles.

To properly perform the segmentation process and therefore to obtain the purest representation of the displayed objects, it is very important to choose the right scale for image segmentation (i.e. scale parameter). Two other significant factors are the object shape and compactness that affect the homogeneity of the created segments. Their values vary between 0 and 1 . Shape factor affects the shape of the segments, with emphasis on spectral homogeneity or objects shape. Compactness factor affects the smoothness vs. compactness of the objects shape (Myint et al. 2011). Segmentation scale value depends primarily on the spatial resolution of images inputting the segmentation process as well as the expected size of created segments (objects) (Majlingová 2007). The lower value of the scale parameter (e.g. 10) produces smaller size objects, while the higher value (e.g. 50) produces larger objects with greater heterogeneity of pixels within the object.

Owing to the size and heterogeneity of an area and forest, the shape factor was set to 0.1 , i.e. with low weight to form the shape of segments, and thus greater weight to the spectral homogeneity of pixels. Compactness factor was set to the mean value (0.5), with no enhanced emphasis on compactness or smoothness of objects. These values were chosen regarding heterogeneous structure of forest (different size and shape of crowns). With determining the most accurate value of scale parameter for image segmentation and its verifying dealt several works in the past (Drăguț et al. 2010; Myint et al. 2011; Kardoš et al. 2013; Drăguț et al. 2014).

For the purposes of this study, there was selected the "Estimation of Scale Parameter" (ESP) tool, which is used to estimate the scale parameter for multiresolution segmentation in eCognition. ESP allows select the default value of scale parameter, step size of scale parameter value incrementing, the number of repetitions "," Shape and Compactness parameter values, on which iteratively performs segmentation of more-layered image at different levels of scale parameter, for which calculates the local variance of identified segments. Based on the graphic evaluation of the Local Variance (LV) and Rate of Change (ROC) calculations, which reflect the change of variance at different levels, it allows estimate the most appropriate scale parameter value for the image. The biggest changes of $\mathrm{LV}$ expressed by ROC values represent potentially the biggest changes in the meaning of segmentation and hence the representation of individual segments (Drăguț et al. 2014).

ESP was set to calculate the segmentation for the initial value of the scale parameter (25) and then iteratively calculate with incrementing the parameter value up to value 150 . Overall, there were calculated 126 segmentations. The tool is computationally demanding, therefore there was used the image subset with an extent of about 36 hectares, to calculate that properly represented the heterogeneity of the experimental area. 


\subsection{Classification process}

The basis for assessment is the comparison of accuracy of tree species composition classification as on a basis of aerial multispectral imagery application as in combination with ALS data. There were performed two classifications based on a different data sources. At first, only the orthophoto images (3 RGB bands and 3 CIR bands) were used. At second, the combination of orthophoto images (3 RGB bands and 3 CIR bands) and raster layers derived from ALS data were used. These ALS-derived layers were represented by the nDSM layer, which represents the object height above the ground and Intensity layer that characterizes the reflection of surface.

For the both classifications of group of tree species, there was applied the standard nearest neighbour (SNN) classifier with setting the emphasis to mean values of pixels for each band of orthophoto image. Furthermore, in second case, there were classified those image segments using membership function, on the basis of the nDSM layer, which average height was less than $3 \mathrm{~m}$. Those segments were assigned to the "Ground" class and they represented a surface of relief with low objects. Segments with an average height of $3 \mathrm{~m}$ or more were further assigned into 3 classes: "Deciduous", "Coniferous" and "Shadow", using another 7 layers, i.e. channels, (3 RGB, 3 CIR and Intensity layer).

The classification was carried out based on defining the characteristics of each class by creating the "Samples" (training sets), in which a characteristic samples (objects) were assigned. The weight of all layers in the classification process was set to 1.0 .

\subsection{Verification process}

Evaluation of the classification accuracy was provided using the classification error matrix and calculation of classifications accuracy. For each classification and also the class, we calculated the Kappa coefficient (Dou et al. 2007), which indicates the proportionate reduction in error generated by a classification process, compared to the error of a completely random classification (equation 1).

$$
K=\frac{P_{0}-P_{e}}{1-P_{e}}
$$

where $P_{o}$ - the proportion of observed agreement, $P_{e}$-the proportion of random agreement.

For determining the accuracy of the classifications, there was created a verification layer of tree species composition in the model area, on the basis of RGB and CIR orthophoto images. The verification layer consisted of 50 segments situated within the randomly generated circular plots in ArcGIS with diameter of $25 \mathrm{~m}$, and with the total area of $24,200 \mathrm{~m}^{2}$ (Fig. 1). To each segment or its part was assigned one of the specified classes (ground, shadow, deciduous, coniferous), based on visual assignment. This verification layer was used to determine the accuracy of both classifications.

\section{Results}

\subsection{Segmentation results}

The aim of the segmentation was to generate segments as good as possible to represent the reality displayed in the images. To determine the most appropriate scale (scale parameter) for the multiresolution segmentation the Estimation of Scale Parameter (ESP) tool was applied. Graphical representation of the Local variance (LV), Rate of Change (ROC) calculations and detail of ROC are shown in Fig. 2. In accordance to calculation results, there was chosen the segmentation scale parameter with value of 125 , where is the highest value change of the ROC.

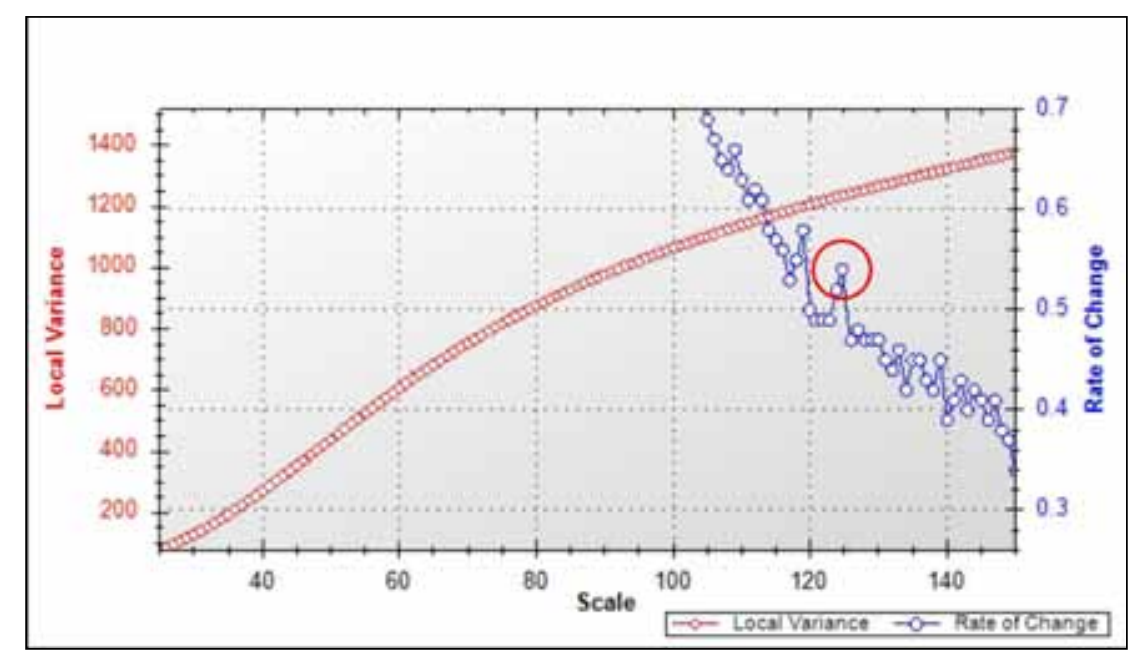

Fig. 2. Visualisation of Rate of Change in Estimation of Scale Parameter (ESP) environment (value 125 is in circle). 

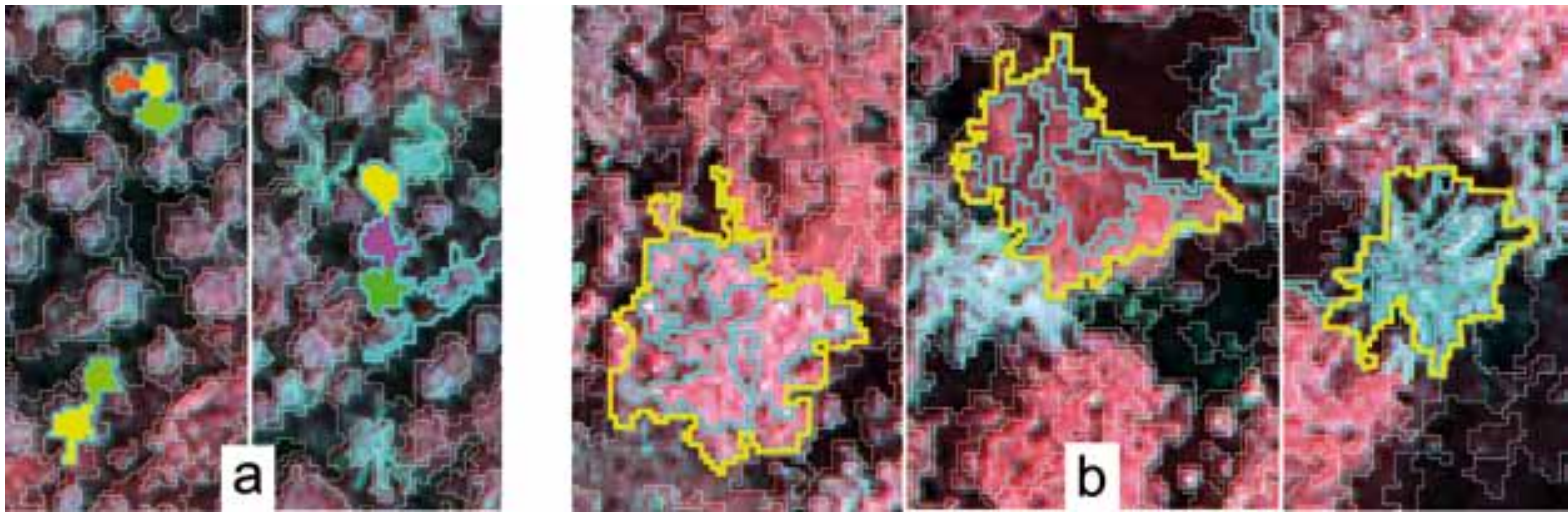

Fig. 3. Results of segmentation, a: in one segment (blue line) is more than one crown (coloured polygons); b: mature canopy (yellow line) consists from more than one segment (blue lines).

The segmentation result was visually compared with the orthophoto images. The results are characterized with over-segmentation of objects in the regions with mature forests (with broad crowns), i.e. in an average, one crown consists of several segments (Fig. 3b). Nevertheless, those results are acceptable, in accordance to the extent of the territory, heterogeneity of tree crowns, illuminated and shaded parts of the tree crowns and the variable quality of orthophoto images on a large area. In contrast, the segmentation of younger stands, characterized with smaller tree crowns, was more accurate in terms of the size. The youngest stands with the smallest crowns were characterized with under-segmentation, i.e. one segment contained more crowns of the same group of tree species (Fig. 3a). In terms of tree crowns canopy closure, also the determination of the shape of individual tree crowns was difficult, especially for young deciduous trees with a full canopy closure.

\subsection{Classification results}

Into the class "Coniferous", there was assigned 1,102.99 hectares (50\% of the whole experimental area). 942.96 hectares (42\%) was assigned into the "Deciduous" class. 151.63 hectares $(7 \%)$ was assigned into the "Ground" class and only 25.48 hectares (1\%) into the "Shadow" class (Fig. 4).

To "Ground" class (yellow coloured), there were classified the areas representing mainly the landscape outside the forests such as roads and grasslands. Inside the forest the "Ground" class objects were found in the gaps of tree crowns and in stands with low stocking and opened canopy closure. The largest areas of "Ground" were located in the eastern part, on the ridge, where there are damaged stands with lower stem density. Identifiable are also the part of forest roads over which there are not the tree crowns. In the territory, it is possible to distin-

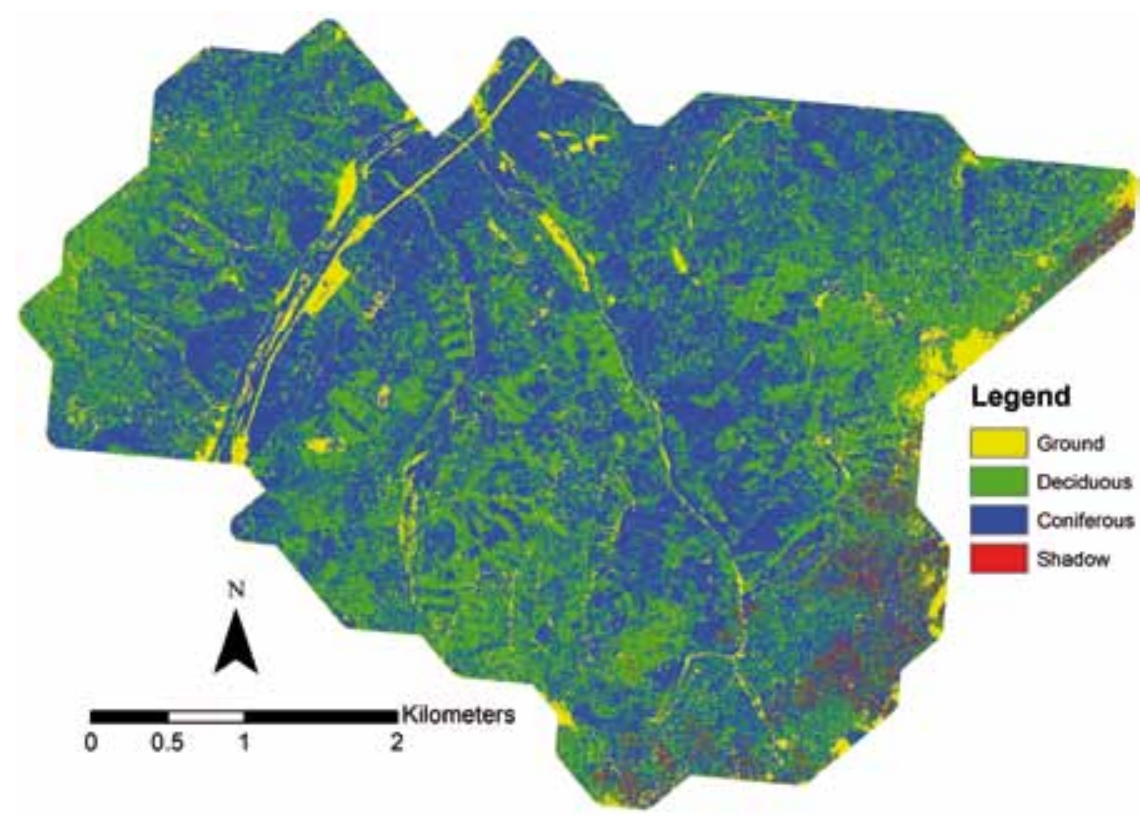

Fig. 4. Classification result of experimental area. 
guish the spatial distribution of deciduous (green colour) and coniferous trees (blue colour). Red colour represents the class "Shadow". It is represented primarily in the north-eastern and south-eastern parts of the territory, which is associated with worse quality of the underlying multispectral imagery of this area, where some flight lines were realized in different time.

The results of classification without the use of ALS data are shown in the classification error matrix (Table 1) and results with the use of ALS data are shown in the classification error matrix (Table 2). Tables show area conjunction $\left(\mathrm{m}^{2}\right)$ of each class derived based on classification process and reference data. For each classification class, there was calculated User's Accuracy (UA) and for each class of reference data was calculated Producent's Accuracy (PA). UA expresses the probability that a pixel is included in the class truly represents this class also in the field. PA expresses how many proportions of reference pixels were assigned to the class.

The results of classification (with the use of ALS data are shown in the classification error matrix in $\mathrm{m}^{2}$ (Table 2).

The overall classification accuracy, without the use of ALS data, was lower (84.14\%), when compared to accuracy of the classification with application of ALS data (87.42\%). Improvement of overall accuracy by $3.28 \%$ represents $792 \mathrm{~m}^{2}$ large area of verification layer. Improvement represents 72.92 hectares of total area and correct classified area is $1,943.40$ hectares large. The value of Kappa coefficient, expressing the correlation between the reference data and classification results, and excluding the matches by chance, increased from 0.7080 to 0.7774 . Increasing this value means that the ALS data application in the classification process removed $6.96 \%$ of the errors that would be produced by random classification process.

In the classification without application the ALS data, there was classified c.a. $5.5 \%\left(1,345 \mathrm{~m}^{2}\right)$ of the total experimental area into one of two classes of group of tree species, although in the verification layer those areas were assigned to the "Ground" class. Applying the ALS data, there was correctly classified the area of $1,167 \mathrm{~m}^{2}$ and user accuracy reached $81.60 \%$. Area with extent of $263 \mathrm{~m}^{2}$ was classified incorrectly and assigned to another class of group of tree species. The reason could be the position shift between the orthorectified aerial images and point cloud of ALS data, which differ in the way of surface scanning. The farther are the objects displayed in the image from the flight path, the greater is the position error of identical objects from the point cloud.

At the same time, the representation of "Shadow" class was reduced of approximately $183 \mathrm{~m}^{2}$. This is attributed to the shift of this area to "Ground" class. In the shaded parts of the area, there could not be identified whether it is a ground or vegetation, while with the use of ALS data a part of this area was identified as the "Ground". Due to the high precision of the laser data and the use of multiple remote sensing materials, the area assigned to the "Ground" class, and overlaying with the "Shadow" class of the verification layer, was considered for correctly classified.

In terms of the classification of tree species composition accuracy, the User's Accuracy (UA), expressing the probability that the pixel included in the class truly represents this class also in the field, increased by $5.36 \%$ in case of deciduous and by $2.80 \%$ in case of coniferous. The kappa coefficient increased from 0.7245 , respectively 0.7362 , to value of 0.7667 , respectively 0.7676 . The producer's accuracy (PA), expressing the accuracy with which the reference pixels have been included in the class decreased in case of "Deciduous" and "Coniferous" classes, due to the incorrect classification of the "Ground" class, which was identified as the "Deciduous" or "Coniferous" class, in comparison with the verification layer. The reasons for this misleading assignment as well as the reduction of the accuracy of shadow classification were described above.

Table 1. Error matrix of classification without using airborne laser scanning data in $\mathrm{m}^{2}$.

\begin{tabular}{|c|c|c|c|c|c|c|c|}
\hline & \multirow[b]{2}{*}{ Class } & \multicolumn{5}{|c|}{ Reference data } & \multirow{2}{*}{$\begin{array}{l}\text { UA } \\
\text { [\%] }\end{array}$} \\
\hline & & Ground & Deciduous & Coniferous & Shadow & Total & \\
\hline \multirow{6}{*}{ 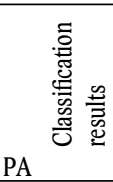 } & Ground & 0.00 & 0.00 & 0.00 & 0.00 & 0.00 & - \\
\hline & Deciduous & 547.81 & 8194.61 & 810.72 & 111.02 & 9664.16 & 84.79 \\
\hline & Coniferous & 597.35 & 1754.56 & 11591.57 & 34.30 & 13977.78 & 82.93 \\
\hline & Shadow & 0.00 & 1.16 & 0.00 & 672.20 & 673.36 & 99.83 \\
\hline & Total & 1145.16 & 9950.33 & 12402.29 & 817.52 & 24315.30 & - \\
\hline & {$[\%]$} & 0.00 & 82.36 & 93.46 & 82.22 & \multicolumn{2}{|c|}{ Overall accuracy: 84.14} \\
\hline
\end{tabular}

UA (User's Accuracy) - the probability that the pixel included in the class truly represents this class also in the field; PA (Producent's Accuracy) - proportion of reference pixels which were assigned to the class.

Table 2. Error matrix of classification with using airborne laser scanning data in $\mathrm{m}^{2}$.

\begin{tabular}{|c|c|c|c|c|c|c|c|}
\hline & \multirow{2}{*}{ Class } & \multicolumn{5}{|c|}{ Reference data } & \multirow{2}{*}{$\begin{array}{l}\mathrm{UA} \\
{[\%]}\end{array}$} \\
\hline & & Ground & Deciduous & Coniferous & Shadow & Total & \\
\hline \multirow{6}{*}{ 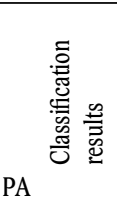 } & Ground & 1167.05 & 109.99 & 153.11 & 0.00 & 1430.15 & 81.60 \\
\hline & Deciduous & 16.10 & 8192.19 & 768.66 & 109.60 & 9086.55 & 90.16 \\
\hline & Coniferous & 160.52 & 1703.92 & 11400.94 & 34.02 & 13299.40 & 85.73 \\
\hline & Shadow & 0.00 & 1.16 & 0.00 & 489.78 & 490.94 & 99.76 \\
\hline & Total & 1343.67 & 10007.26 & 12322.71 & 633.40 & 24307.04 & - \\
\hline & {$[\%]$} & 86.86 & 81.86 & 92.52 & 77.33 & \multicolumn{2}{|c|}{ Overall accuracy: 87.42} \\
\hline
\end{tabular}


Slightly different surface area of the classes in a comparison of the two classifications is caused by the slight variations in the geometry of the objects.

\section{Discussion and conclusions}

In this paper we present the use of ALS data and evaluation of their contribution in the process of object-oriented classification of tree species composition of diverse forests in eCognition Developer 9 software. Comparison of classification accuracyvalues, with and without ALS data application, confirmed its increase and positive contribution in case of ALS data application in the classification of tree species composition, in this case to the deciduous and coniferous tree species.

To derive the appropriate values of scale parameter for image segmentation in eCognition Developer 9, was used the ESP tool, which by comparing the local variance values for each value of scale parameter set derives the Rate of Change value. The scale parameter value for the images with a spatial resolution of $0.2 \mathrm{~m}$, to determine the species composition assigned to deciduous and coniferous trees) was set to value 125 . Since the ESP tool is computationally demanding, scale parameter identification was carried out only on the subset of the images. Kardoš et al. (2013) recommended set the scale parameter in the range of 30-40 for images with a spatial resolution of 0.2 to $0.5 \mathrm{~m}$. The achieved accuracy of identification of various tree species ranged from $48 \%$ to $84 \%$. In our study the greater value of scale parameter was sufficient. At this value, the individual tree crowns were divided into several segments according to the illumination of the crown, but they quite accurately represented the shape of the crown in the higher parts of the stands. Thus, in the subsequent classification, there did not occurred potential problem with incorrect identifying the tree crowns outlines.

According to the results of accuracy of both classifications, it can be stated that the use of ALS data in the classification process improved the accuracy of the group of tree species identification. In addition to improving the overall accuracy of the classification, it is evident that also the accuracy of classification of the two main groups (classes) of stand vegetation (deciduous and coniferous) was increased. The degree of compliance, expressed by Kappa coefficients were also improved for both classes, for "Deciduous" from 0.7245 to 0.7667 and for "Coniferous" from 0.7362 to 0.7676 . Kappa coefficient $K=0$ means a random classification and $\mathrm{K}=1$ means a perfect agreement. These values represent a very good level of consistency according to the classification made by Landis \& Koch (1977).

In terms of the distinguishing between the classes of group of tree species, seems to be the combination of CIR and RGB images to be very useful. The CIR images alone are applicable for tree species identification (Holmgren et al. 2008), on them can be better identified the coniferous. RGB images provide further spectral data in individual channels useful for the classification process to help to distinguish the tree species especially in the less illuminated or shadowed parts of the crown or stands. Adding the nDSM and Intensity layers to the classification process provides additional information on position, respectively the nature of the surface of the object, which has a positive impact on the accuracy of classification, in accordance to the results achieved. The appropriateness of using the ALS data for the object-oriented classification is confirmed by the work of Pascual et al. (2008) and Tomljenovic et al. (2016). Zhang et al. (2013) reached the highest classification accuracy of forests using a combination of aerial images and ALS data - DEM, Intensity and topographic information. Fassnacht et al. (2016) published, the most suitable RS data for tree species identification are hyperspectral images, but for classification of forest with a small number of tree species is suitable to use combination of ALS data and multispectral images. This combination seems the best for Slovak conditions too, because hyperspectral images are not usually available for forest sector.

The problematic part of the classification process and use of a combination of different data sources remains their mutual spatial (position) shift. Orthorectified images display objects in the image the more distorted the more rugged is terrain and the farther away are the objects from the axis of the airplane during the scanning. This is reflected in an unnatural shape of the crown. On the other hand, the point cloud of laser scanning is characterized precisely determined position of each ray reflected by the object in the $3 \mathrm{D}$ space $(\mathrm{X}, \mathrm{Y}$, $\mathrm{Z}$ ), and therefore, in the point of greatest distortion of the images, occurs the spatial displacement between the images and the ALS layers. Practically this is manifested by the fact that while a certain area has been classified as "Ground", in the distorted image it corresponded to one or more tree crowns, which were further classified into classes "Deciduous" or "Coniferous".

According to the authors, for possible further improvement of the classification results would be appropriate to use nDSM layer for definition and derivation of several vertical layers of stand vegetation. It would be useful to define individual classes and training sets (samples), and further provide a classification for each layers. Such a process is likely to improve the classification of tree species in the lower parts of forest stands, often represented by darker (shaded) parts of the image. Utilisation of research plots established in the field seems to be a suitable basis for the creation of a reference layer of tree species, distinguishing the different types of trees.

\section{Acknowledgments}

This research was supported by the Slovak Research and Development Agency (project APVV-0439-12). 


\section{References}

Andersen, H. E., Breindenbach, J., 2007: Statistical Properties of Mean Stand Biomass Estimators in a LidarBased Double Sampling Forest Survey Design. Proc. ISPRS III/3, III/4, V/3 and VIII/11., "LaserScanning 2007 and SilviLaser 2007“, p. 8-14.

Baatz, M., Schäpe, M., 2000: Multiresolution segmentation - An optimization approach for high quality multi-scale image segmentation. In: Strobl, J., Blaschke, T., Griesebner, G. (eds.): Angewandte Geographische Informations- Verarbeitung XII. Wichmann Verlag, Karlsruhe, p. 12-23.

Benz, U.C., Hofmann, P., Willhauck, G., Lingenfelder, I., Heynen, M., 2004: Multi-resolution, object-oriented fuzzy analysis of remote sensing data for GIS-ready information. ISPRS Journal of Photogrammetry and Remote Sensing, 58:239-258.

Blaschke, T., 2010: Object based image analysis for remote sensing. ISPRS Journal of Photogrammetry and Remote Sensing, 65:2-16.

Bucha, T., Vladovič, J., Juriš, M., Barka, I., 2010:Aplikácie dialkového prieskumu Zeme využitel'né v prácach HÚL. In: Súčasnost'a budúcnost'hospodárskejúpravy lesov na Slovensku, $10 \mathrm{p}$.

Cleve, C., Kelly, M., Kearns, F. R., Moritz, M., 2008: Classification of the wildland-urban interface: A comparison of pixel- and object-based classifications using high-resolution aerial photography. Computers, Environment and Urban Systems, 32:317-326.

Debella-Gilo, M., K. Bjørkelo, K., Breidenbach, J., Rahlf, J., 2013: Object-Based analysis of aerial photogrammetric point cloud and spectral data for land cover mapping. ISPRS - International Archives of the Photogrammetry, Remote Sensing and Spatial Information Sciences, 40:63-67.

Drăguț, L., Tiede, D., Levick, S. R., 2010: ESP: A tool to estimate scale parameter for multiresolution image segmentation of remotely sensed data. International Journal of Geographical Information Science, 24:859-871.

Drăguț, L., Csillik, O., Eisank, C., Tiede, D., 2014: Automated parameterisation for multi-scale image segmentation on multiple layers. ISPRS Journal of Photogrammetry and Remote Sensing, 88:119-127.

Dou, W., Ren, Y., Wu, Q., Ruan, S., Chen, Y., Bloyet, D., Constans, J-M., 2007: Fuzzy kappa for the agreement measure of fuzzy classifications, Neurocomputing, 70:726-734.

Fassnacht, F. E., Latifi, H., Stereńczak, K., Modzelewska, A., Lefsky, M., Waser, L. T. etal., 2016: Review of studies on tree species classification from remotely sensed data. Remote Sensing of Environment, 186:64-87.

Halvoň, L., 2011: Posúdenie presnosti vyhodnotenia leteckých meračských snímok metódami digitálnej fotogrametrie pri lesníckom mapovaní. In: Racionalizácia lesníckeho mapovania - zborník referátov, Zvolen, Technická univerzita vo Zvolene, p. 14-22.
Heinzel, J., Koch, B., 2012: Investigating multiple data sources for tree species classification in temperate forest and use for single tree delineation. International Journal of Applied Earth Observation and Geoinformation, 18:101-110.

Holmgren, J., Persson, Å., Söderman, U., 2008: Species identification of individual trees by combining high resolution LiDAR data with multi-spectral images. International Journal of Remote Sensing, 29:15371552.

Kardoš, M., Medved'ová, A., Supek, Š., Škodová, M., 2013: Object-oriented classification of tree species in digital aerial photos of landslide area. Zprávy lesnického výzkumu, 58:195-205.

Kim, M., Madden., M., 2006: Determination of optimal scale parameter for alliance-level forest classification of multispectral IKONOS image. Proc. of First International Conference on Object-based Image Analysis (OBIA 2006), Salzburg, XXXVI-4/C42.

Kressler, F., Steinnocher, K., 2008: Object-oriented analysis of image and LiDAR data and its potential for dasymetric mapping applications. In: Blaschke, T., Lang, S., Hay, G. J. (eds.): Object Based Image Analysis. Springer, Heidelberg, Berlin, p. 611-624.

Korpela, I., Tuomola, T., Välimäki, E., 2007: Mapping forest plots: An efficient method combining photogrammetry and field triangulation. Silva Fennica, 41:457-469.

Landis, J. R., Koch, G. G., 1977: The measurement of observer agreement for categorical data. Biometrics, 33:159-174.

Leppänen, V. J., Tokola, T., Maltamo, M., Mehtätalo, L., Pusa, T., Mustonen, J., 2008: Automatic delineation of forest stands from LiDAR data. Presented at GEOgraphic Object-Based Image Analysis for the 21st Century, Calgary, 6 p.

Majlingová, A., 2007: Digitálna obrazová analýza dát DPZ s vysokým priestorovým rozlíšením a jej využitie v lesníctve. In: Sympozium GIS Ostrava. Ostrava, VŠB TU, 16 p.

Machala, M., Zejdová, L., 2014: Forest mapping through Object-based image analysis of multispectral and LiDAR Aerial data. European Journal of Remote Sensing, 47:117-131.

Maltamo, M., Packalen, P., 2014: Species-specific management inventory in Finland. In: Maltamo, M., Næsset, E., Vauhkonen, J. (eds.): Forestry Applications of Air-borne Laser Scanning: Concepts and Case Studies. Springer, Dordrecht, p. 241-252.

Myint, S. W., Stow, D., 2011:An Object-Oriented Pattern Recognition Approach for Urban Classification. In: Urban Remote Sensing: Monitoring, Synthesis and Modeling in the Urban Environment, p. 129-140.

Ørka, H. O., Wulder, M. A., Gobakken, T., Næsset, E., 2012: Subalpine zone delineation using LiDAR and Landsat imagery. Remote Sensing of Environment, 119:11-20. 
Pascual, C., García-Abril, A., García-Montero, L. G., Martín-Fernández, S., Cohen, W. B., 2008: Objectbased semi-automatic approach for forest structure characterization using lidar data in heterogeneous Pinus sylvestris stands. Forest Ecology and Management, 255:3677-3685.

Petr, M., Smith, M., Suaréz, J. C., 2010: Object-based approach for mapping complex forest structure phases using LiDAR data. In: International Archives of the Photogrammetry, Remote Sensing and Spatial Information Sciences - ISPRS Archives, 6 p.

Pippuri, I., Suvanto, A., Maltamo, M., Korhonen, K.T., Pitkänen, J., Packalen, P., 2016: Classification of forest land attributes using multi-source remotely sensed data, International Journal of Applied Earth Observation and Geoinformation, 44:11-22.

Rittl, T., Cooper, M., Heck, R. J., Ballester, M. V. R., 2013: Object-Based method outperforms per-pixel method for land cover classification in a protected area of the brazilian atlantic rainforest region. Pedosphere, 23:290-297.

Sasaki, T., Imanishi, J., Ioki, K., Morimoto, Y., Kitada, K., 2012: Object-based classification of land cover and tree species by integrating airborne LiDAR and high spatial resolution imagery data. Landscape and Ecological Engineering, 8:157-171.

Tiede, D., Lang, S., Hoffmann, Ch., 2006: Supervised and forest type-specific multi-scale segmentation for a one-level-representation of single trees. In: Lang S. et al. (eds.): Bridging remote sensing. 1st international conference on object-based image analysis (OBIA 2006). Salzburg, 5 p.
Tomljenovic, I., Tiede, D., Blaschke, T., 2016:A building extraction approach for Airborne Laser Scanner data utilizing the Object Based Image Analysis paradigm, International Journal of Applied Earth Observation and Geoinformation, 52:137-148.

Wack, R., Schardt, M., Barrucho, L., Lohr, U., Oliveira, T., 2003: Forest inventory for eucalyptus plantations based on airborne laserscanner data. WG III/3 Workshop ,3-D reconstruction from airborne laserscanner and InSAR data“. Dresden, $7 \mathrm{p}$.

Wang, Z., Boesch, R., 2007: Color- and texture-based image segmentation for improved forest delineation. IEEE Transactions on Geoscience and Remote Sensing, 45:3055-3062.

Wang, Z., Boesch, R., Ginzler, C., 2012: Forest delineation of aerial images with Gabor wavelets. International Journal of Remote Sensing, 33:2196-2213.

Yu, Q., Gong, P., Clinton, N., Biging, G., Kelly, M., Schirokauer, D., 2006: Object-based detailed vegetation classification with airborne high spatial resolution remote sensing imagery. Photogrammetric Engineering \& Remote Sensing, 72:799-811.

Zhang, C., Xie, Z., Selch, D., 2013: Fusing lidar and digital aerial photography for object-based forest mapping in the Florida Everglades, GIScience \& Remote Sensing, 50:562-573. 